\title{
Evaluating Cross-Country Policy Learning in Public Administration: The Case of Qatar-Singapore Partnership in Regional Training Centre for Public Administration (RTCPA)
}

\author{
M. Evren Tok $^{1} \&$ Duygu Sever ${ }^{2}$
}

\begin{abstract}
This article examines the interaction between Singapore and Qatar as an instance of policy transfer between a successful case of development and an ambitious case in transition through exclusive focus on human capital development in public policy making and public administration. As Qatar's modernization continues in pace and intensity, increasing exposure to the forces of globalization induce major changes in Qatar's nation- and state-building processes. This process requires strong state capacity. Given the goal of enhancing state capacity, a central strategy has been balancing global and local forces. An integral element of this strategy has been learning from other's experiences and engaging in policy transfer and learning.
\end{abstract}

As a tool for this process of policy transfer, the article further evaluates the case of SingaporeQatar Asia-Middle East Dialogue (AMED) Regional Training Centre for Public Administration (RTCPA) in Doha, Qatar, as a mechanism to foster this policy transfer. Jointly established by the governments of Singapore and Qatar in November 2006, The RTCPA has been providing training courses to officials from AMED member countries in the areas of public administration, trade promotion, urban planning, environment management, information communication technology, sustainability development, public finance and quality management.

By focusing on RTCPA as a case, the research targets to explore to what extent Singapore's experience and approach towards governance and policymaking, management tools, and information and communication technologies (ICT) that have been effectively utilised in the public sector, have shaped Qatari efforts in its own path of development. Data have been gathered from key reports related to Qatar National Vision 2030, official documents of both Qatar and Singapore, as well as from official diplomatic communications among their governments. Additionally, experiences of previous RTCPA training participants from the Ministry of Administrative Development, Labour and Social Affairs of Qatar were also incorporated into the analysis. The study suggests that this evaluation would be a fruitful example in revealing the strengths and weakness of such initiatives and can offer a scheme for insights regarding effective tools of policy learning.

\section{Keywords}

Qatar, Singapore, Singapore-Qatar Asia-Middle East Dialogue, policy transfer, policy learning, public administration

\footnotetext{
${ }^{1}$ Assistant Dean of Innovation and Community Engagement, Associate Professor of Islam and Global Affairs, College of Islamic Studies, Hamad Bin Khalifa University, Doha/Qatar. Etok@hbku.edu.qa

${ }^{2}$ PhD Candidate, International Relations and Political Science, Koç University, Istanbul/Turkey.
} 


\section{Introduction}

For the last decades, Qatar has put forward ambitious national development strategies. The Qatar National Vision (2008) and the Qatar National Development Strategy (2011-2016) (succeeded, as of December 2017, by the Second National Development Strategy (2018-2022) propose such vast, intensive, and expensive development that earlier literature designated Qatar as a "transformative state" (Tok, Alkhater, \& Pal, 2016). Development on this scale, even for a small country with enormous wealth, is challenging from a public management perspective. It will only work if both people and systems are in place to implement it. This requires the education as well as the adaptation of existing human capital in public administration into the new systems targeted for future strategies and vision. The first national development strategy, for example, contained plans for 170 projects, 10 of which were dedicated to enhancing public administration. A benchmarking exercise was undertaken by Qatar authorities for five countries to help identify the building blocks for Qatar's transition to modernization: Australia, Canada, Norway and Singapore (for international best practices), and the UAE (for a regional comparison). The relationship with Singapore has turned out to be one of deepest and most sustained.

Giving justice to its anthem motto "Majulah Singapura" (Onward, Singapore), Singapore has been transforming itself significantly. Today, Singapore envisions itself as a "Smart Nation" and continues to its transformation through technology, digital innovation and a good functioning economy to meet the diverse and changing needs of its citizens. All domains, including public sector are supported by Singapore Government to facilitate policies and relevant 
legislations required for innovations and new ideas in the public and private sector (Why Smart Nation, 2018). As indicated in Singapore Cooperation Program, "as a country whose only resource is its people, Singapore believes that human resource development is vital for economic and social progress". Accordingly, Singapore has undertaken the role to provide technical assistance to other developing countries since 1960s, just like it benefited itself from trainings provided by other countries and international organisations (Singapore Cooperation Program, 2018).

Qatar has been trying to learn from this successful model of country that is also small, and which since 1965 rapidly transitioned, in the words of its founding Prime Minister, Lee Kuan Yew, from "third world to first" (Yew, 2000). In different occasions, state representatives from both parties have been highlighting many shared factors between Qatar and Singapore. For instance the first female President of Singapore, Halimah Yacob, highlighted in 2017 the regional vital role both countries play (The Peninsula, 2017) and stated: "the trajectories of growth and development of our two countries show that success does not depend on size," (The Straits Times, 2017). Apart from their size and enthusiasms for sustainable development, Qatar and Singapore include other similarities too, such as pro-development leadership, investment in education and emphasis on human capital. However, they are also markedly different in history, culture, ethnicity, religion, and in resources.

In the light of these similarities and differences, this research examines the interaction between Qatar and Singapore through the lenses of policy transfer and questions through what means the policy learning works? The research aims to contribute to the literature by not only focusing on detecting the policy areas that are prioritised in the policy transfer but also on the concrete tools specifically designed for catalysing the transfer through trainings. By examining, the Regional Training Centre for Public Administration (RTCPA) in Qatar, which is a 
partnership between Singapore and Qatar that concentrates on the development of human capital through training civil servants to excel in their different capacities and skills in pursuit of better public service, the analysis aims to evaluate the scope and impact of this training platform as a solid tool for policy transfer, which can be a benchmark for further cross-country tools and initiatives targeting policy learning.

The article addresses these questions first by explaining further why we expect a policy transfer "from" Singapore "to" Qatar and by reviewing their bilateral relations. Following this, we put under the spotlight the case of the Singapore-Qatar interaction within the Asia-Middle East Dialogue (AMED) with specific focus on the Regional Training Centre for Public Administration (RTCPA) in Doha, Qatar. RTCPA was jointly established by the governments of Singapore and Qatar in November 2006. RTCPA has been providing training courses to officials from AMED member countries ${ }^{3}$ in the areas of public administration, trade promotion, urban planning, environment management, information communication technology, sustainability development, public finance and quality management. AMED itself is part of initiatives under the Singapore Cooperation Programme, which was consolidated in 1992 under the Singaporean Ministry of Foreign Affairs ${ }^{4}$.

Our interest is therefore, in the training provided to Qatari officials through the RTCPA, specifically designed to talk about Singapore experience and Singaporean public administration practices and techniques. What has been its content? How has it been modified for the Qatari

\footnotetext{
${ }^{3}$ AMED's membership is open to 49 countries and the Palestinian National Authority (PNA). The 49 countries are Afghanistan, Algeria, Bahrain, Bangladesh, Bhutan, Brunei, Cambodia, China, Comoros, Djibouti, Egypt, India, Indonesia, Iran, Iraq, Japan, Jordan, Kazakhstan, Kuwait, Kyrgyzstan, Laos, Lebanon, Libya, Malaysia, Maldives, Mauritania, Morocco, Myanmar, Nepal, Oman, Pakistan, Philippines, Qatar, Republic of Korea, Saudi Arabia, Singapore, Somalia, Sri Lanka, Sudan, Syria, Tajikistan, Thailand, Tunisia, Turkey, Turkmenistan, UAE, Uzbekistan, Viet Nam, and Yemen.

${ }^{4}$ Other initiatives include: the Small Island Developing States Technical Cooperation Programme (SIDSTEC) and the Initiative for ASEAN Integration (IAI), launched in 2000, with four training centres in Phnom Penh, Vientiane, Yangon and Hanoi.
} 
context, if at all? How successful has the transfer and application been in the Qatari public service? We suggest this evaluation would be a fruitful example in revealing the strengths and weakness of such initiatives and can offer a scheme for insights regarding effective tools of policy learning. Our methodology follows the qualitative, in depth analysis of official documents from both Qatar and Singapore, of key reports related to Qatar National Vision 2030, as well as official diplomatic communications among Government and Foreign Ministry representatives from involved AMED countries. Additionally, experiences of previous RTCPA training participants from the Ministry of Administrative Development, Labour and Social Affairs of Qatar are also incorporated into the analysis. Nevertheless, a major limitation to the research is extreme lack of available data regarding RTCPA.

Our theoretical framework is grounded in recent work on policy transfer and policy learning. The contribution of this article is both to an understanding of the specifics of the QatarSingapore relationship, and to the theoretical appreciation of the micro-dynamics of policy transfer, specifically as it is channelled through government-to-government training programs of this sort. Moreover, as our theoretical framework will be elaborating more, we suggest that RTCPA is an interesting case for "actual" policy learning, totally based on voluntary initiatives of Qatar and Singapore, without any conditionality motivation or obligation under the enforcement of a supranational authority. We suggest that the positive aspects as well as the shortcomings of such an effort can set example for other inter-state learning mechanisms and inspire policy transfer literature.

\section{Theoretical Framework: Policy Transfer and the Micro-Dynamics of Public}

\section{Administration Training}

Policy transfer has seen a resurgence of theoretical and empirical interest in the last decade. At its simplest, it involves the transfer, modification and implementation of policy 
paradigms, programs and/or tools from one jurisdiction to another. Overall "policy transfer, emulation and lesson drawing all refer to a process in which knowledge about policies, administrative arrangements, institutions etc. in one time and/or place is used in the development of policies, administrative arrangements and institutions in another time and/or place" (Dolowitz \& Marsh, 1996, p. 344).

The nature of the transfer and how it takes place is crucial. At this point it is useful to make the distinction between strategic learning and social learning in policy transfer. For instance in regional supranational institutions, such as the European Union which has market integration and policy pressures (Schneider and Hage, 2008, 6), through "formal accession conditions" which give the supranational entity "a leverage compared to the candidates which have to comply with the demands" (Grabbe, 2002, p. 3; Sever, 2018) we can talk about a "process of change at the domestic level in which the member states adapt their processes, policies, and institutions to new practices, norms, rules, and procedures that emanate from the emergence of a system of governance" (Börzel and Risse, 2003). This adaptation process targets to "overcome the policy misfits" between domestic level and supranational level to "reach distinct structures of governance in the political, legal and social realms" (Risse, Cowles and Caporaso 2001, p. 3, Sever, 2018).

When the actors imitate certain standards in line with their appropriateness to their national agendas (Bürgin, 2014, p. 464) or when an actor learns how to cope with a problem without changing preferences" just for the sake of problem solving (Bürgin, 2014, p. 464; Checkel, 1998; Sever, 2018), we can talk about "strategic learning" (Schimmelfennig and Sedelmeier, 2005, p. 10). Strategic learning especially applies in cases where the actors are motivated by a reward of exclusive membership or by a necessity to fulfill certain conditionality. 
In such occasion, schemes are simply transferred from the supranational body to the domestic context with the motivation of membership (Sever, 2018).

In the policy transfer through learning, actors can adjust their strategies or preferences to the given conditions, This, however, "does not mean an automatic transfer of the reforms into "daily life" through actors who internalize them within their domestic political and normative context." (Sever, 2018, p. 4). That said, although it is rare (Risse, Cowles and Caporaso, 2001, p. 12), the learning can also result in a change in values, interests or identities going way beyond problem solving.

When actors acquire new interests and preferences through interaction with broader institutional contexts, norms or discursive structures "social learning" takes place (Checkel, 1999, p. 548). Unlike lesson drawing of strategic learning which "fails to fulfill the criteria of social learning, this implies a process whereby actors, through interactions with broader institutional contexts (norms and discursive structures), acquire new interests and preferences or even identities" (Checkel, 1999, p. 464). The conditionality factor is out of picture in social learning. In this case, the "logic of appropriateness" guides the process which is driven by values and norms. The actors involved in such an interaction internalize the "the norms and values of the community environment” (Bürgin, 2014, p. 461; Dolowitz and March, 2000; Sever, 2018). This type of learning through socialization process can modify the interests, identities and ideas of the agents (Checkel, 2005, p. 802).

Building on this background we suggest that, in the case of public policy making, while the focus on learning in the transfer process is laudable, there has been little attention to how and through which tools ideas are transferred across countries, and in particular to ideational transfer through training and educational programs for public servants (or aspiring public servants) who are in charge of actually implementing transferred policies or ways-of-conduct. In that respect, 
training and education can be seen as a process of "transnational socialization" that imprints norms on the representatives of national bureaucracies, giving them a shared language and conceptual space that make them "sympathetic interlocutors" with international organizations marketing policy models (Broome \& Seabrooke, 2015).

Among these tools, a largely unexplored mechanism of this type of transfer is specific training modules, programs and initiatives which specifically target Public Policy Making and Public Administration, and aims to "foster emulation and a shared policy language among a community of actors" (Broome \& Seabrooke, 2015, p. 956). These programs of course train students who typically are about to enter public service, and thereby complement the in-service training. However, such programs are usually situated in university departments that also provide advice and training to the public service in their country, and often contribute to bilateral training programs delivered by governments and international organizations. To the extent that the curricula of these programs are designed to international standards, they also become a means whereby policy ideas are transferred in the form of best practice examples or a conventional set of understandings about the content of public administration and public policies (Pal \& Clark, 2016a, 2016b).

In our view, these underappreciated mechanisms of ideational policy transfer serve as "micro-mechanisms" of transfer (Hadjiisky, Pal, \& Walker, 2017), and need to be theorized and studied more closely. In this context, The RTCPA offers an interesting example of a policy transfer tool, through cross-country trainings. While the training centre is open to other members of the AMED as well, its initiation through a Singapore-Qatar partnership represents a voluntary and highly motivated cooperation for policy learning and transfer between a transfer agent and a recipient. 
In terms of quality of its public administration Singapore has been pointed at as a best practice. Qatar, on the other hand, has explicitly adopted a stance of rapid modernization and open borrowing from the best that other countries have to offer (for some time, Doha had numerous signs reminding the populace that "Qatar Deserves the Best"). Given that their partnership rests on a voluntary transfer of public policy between two developing countries, we expect that the nature of the process will be different than it would be in the case between an international organization (IO), such as the IMF, and a developing country, which is usually prevailed by conditionality. Moreover, IOs are generally expected to transfer a more coherent and specific set of policy ideas and practices, keyed often to economic and financial management fields, where certain set of rules or "consensus" is assigned to follow (Broome \& Seabrooke, 2012). Singapore is not an IO, and there is no "Singapore consensus". By the same token, while Qatar may lack policy capacity and expertise, it is not in the same category as a low-income developing country subject to conditionality.

The following section clarifies why and on what background a policy transfer is expected between Qatar and Singapore.

\section{The Background for Policy Transfer: Singapore as "the best practice", Qatar as the}

\section{"learner"?}

The diplomatic interaction between Singapore and Qatar was established in 1984. QatarSingapore High-Level Joint Committee (HLJC) operates as the major the pillar of SingaporeQatar bilateral relations. It is very significant that the only country from the Middle East which has high-level bilateral cooperation mechanisms with Singapore, is Qatar. Since October 2006, when the first meeting of HLJC was held, the two countries has been cooperating in economy, civil service and urban planning, security, civil defence, information technology, communications and legislation. Especially for the last couple of years, in 2016 and 2017, this 
cooperation was further deepened through agreements and memorandum of understandings (MoUs) . To illustrate, the MoUs concluded in March 2016 focused on co-operation on the legal field between the governments of Qatar and Singapore, co- operation in the education field between the Ministry of Education and Higher Education in the State of Qatar and the Ministry of Education in Singapore and on co-operation and exchange in the field of development and capacity building of government officials and sectors' leaders between Qatar Leadership Centre and the Civil Service College in Singapore (Cafiero, 2017).

It is also worth noting that trade constitutes a crucial portion in the bilateral relations. Qatar Chamber's Vice Chairman Mohammed bin Ahmed bin Towar declared on April 16, 2018 that the volume of trade exchange between Qatar and Singapore reached about \$ 6.4 billion at the end of 2017 (Qatar Chamber, 2018). Accordingly, as highlighted by Ambassador of Singapore to Qatar HE Jai Sohan, in 2017, Qatar was Singapore's third largest trading partner in the Middle East (Agonia, 2018). It is therefore, no coincidence that The Singapore Business Council in Qatar (SBCQ) was launched in May 1 ${ }^{\text {st }}, 2018$ as an additional platform to deepen commercial and business links (Peninsula, 2018). These trade initiatives found their basis on agreements such as a "Bilateral Investment Treaty, aimed at opening up opportunities and boosting trade and investment by providing businesses with better protection" (Luo, 2017). Under the bilateral High Level Joint Committee framework, to ensure regular follow-up and optimal implementation of initiatives, parties incorporated the Implementation Monitoring Mechanism (IMM), which conducted its first meeting on April 15, 2018 in Doha. In the meeting, the chairs stated their satisfaction of the progress and agreed on further action and implementation-oriented approach to foster Government-to-Government, Business-toGovernment, and Business-to-Business partnerships for mutual benefits (Cafiero, 2017; Luo, 2017). 
The themes and focus of these agreements and initiatives, listed above, signal us the main policy spheres where we expect policy transfer from Singapore to Qatar. The agreements create a policy transfer environment for sure, yet the real policy learning can take place on actual handson processes through socialization. It is possible to argue that both parties do their best to create this dynamism as they "seek to organise workshops, seminars and conferences to enhance knowledge sharing, provide scientific publications, implement joint professional development projects, developpe leadership skills, exchange experiences and programs in areas of mutual interest and establish institutions in the educational sectors" (Peninsula, 2017).

As these developments take place in bilateral relations, it is crucial to highlight the perception of Singapore as an example of "best-practice" by Qatari policy makers, which indeed leads us to observe a policy transfer and learning from Singapore towards Qatar:

Qatar's growth can be considered in three major periods: the period 2000-2010 is "oil and gas era" which is characterized by 13\% of annual GDP growth. The period between 2010 and 2020, the "Infrastructure Era" consist of a rather lower GDP growth rate, however is a crucial phase for Qatar towards reaching its Vision 2030. Finally the period between 2020 and 2030 is "Sustainable Diversification" era which inherits two major challenges: "the challenge to improve productivity at the same time reducing the influx of low-skilled workers" and "the challenge to create white-collar jobs" to "fill" the infrastructure which is set to be consolidated by 2020 (Qatar Foundation, 2016).

In this context, human development through capable and motivated workforce is one of the main pillars of Qatar National Vision 2030 (QNV 2030). Once QNV 2030 was launched in October 2008, it opened the way for programmes and projects that ensure sustainable prosperity for future generations which resulted in the preparation of the National Development Strategy (NDS) 2011-2016 to "identify specific actions and outcomes to overcome challenges and 
advance QNV 2030 goals” (National Development Strategy, 2011-2016). In line with the infrastructure era 2010-2020, which aims the establishment and consolidation of Qatari institutions, this document offers detailed benchmarking for the drivers and levers of modernization in five countries ${ }^{5}$, identifying best practices in public sector performance around the world (National Development Strategy, 2011-2016, p. 245).

This first NDS includes several references to Singapore and its institutions (such as The Economic Development Board of Singapore) in areas including public sector performance, investment, sustainability, sustainable urbanization, healthy living environment, increasing capabilities for innovation, skills and discovery. In this regard, the following evaluation from NDS 2011-2016 provides a relevant example for Qatar's study:

"Countries use different sets of drivers to measure public sector performance and frame modernization efforts. Singapore, for example, singled out productivity, quality, timeliness, responsiveness, effectiveness, efficiency and accountability in a model to improve public services. No one country demonstrates best practices in every lever. The best practice examples were selected for practical application in Qatar; for instance, Singapore provides a better example of policy and planning for Qatar than does Norway" (National Development Strategy, 2011-2016, p. 246).

Qatar's objective self-assessment is especially striking in these comparisons, which reveals its commitment for detecting its weaknesses, challenges as well as it is ambition to overcome them efficiently. To illustrate NDS 2011-2016 states:

\footnotetext{
${ }^{5}$ The five countries are Australia, Canada, Norway and Singapore, identified for international best practices, and the United Arab Emirates, identified for regional comparison
} 
“The scope of Qatar's exports is limited, especially when compared with that of successful outward-looking economies. Singapore, for example, exported a diverse array of about 4,590 separate products in 2008, compared with about 1,630 from Qatar, $98 \%$ of them (in value terms) linked directly to hydrocarbons or such energy-intensive industries as metallurgy" (National Development Strategy, 20112016, p. 94).

Following this finding, Qatar has set itself the target to "review institutional arrangements to support growth and diversification of the economy" (National Development Strategy, 20112016, p. 74). Similarly, in terms of research and development (R\&D) activities and innovation, Qatar acknowledges that by the time the Strategy report was prepared in 2011, for the last five years Qatar had filed about 14 patents annually, compared to more than 5,000 for Singapore. (National Development Strategy, 2011-2016, p. 99). From 1990 until 2016, more than 40 billion dollars were invested by Singapore government in R\&D to nourish the R\&D ecosystem which consists of "local talent development, financial incentives to attract private sector R\&D, favorable business environment and infrastructure and living standards enhancement" (Qatar Foundation, 2016). Overall, taking these good practices into account, Qatar has clearly developed itself a strategy to "become a major force in scientific and technological discoveries, and to translate knowledge into innovative applications that have tremendous socio-economic impact contributing to transform Qatar into a knowledge-based economy and in turn to support QNV 2030" (Ministry of Development Planning and Statistics, 2012).

In this regard Singapore operated as a reliable partner in transferring its experience on how it overcomes its small size and limited resources to become a prosperous and vibrant economy, consistently ranking as one of the most competitive economies in the world. 


\section{Case Study: Singapore-Qatar Asia-Middle East Dialogue (AMED) Regional Training Centre for Public Administration (RTCPA)}

\section{Asia-Middle East Dialogue (AMED)}

Asia-Middle East Dialogue (AMED) was the brainchild of the Prime Minister of Singapore Goh Chok Tong. It is during his state visits to several Middle East countries in 2003 and 2004 that he recognized the need for a common forum to facilitate cooperation and association between the Asian and Middle East regions. The intention was to create a forum for the two regions, which would supersede various bilateral agreements between individual countries of Asia and Middle East. AMED was catalysed by the idea to foster dialogue and promote greater understanding between Asia and the Middle East on important political, economic and social developments. The first formal Asia-Middle East Dialogue meeting was held in June 2005 in Singapore.

\section{$\underline{\text { Objectives }}$}

AMED's key goal is to develop mutually beneficial cooperation, thus greater understanding, at the people-to-people level as well as governmental level among the two regions. Additionally, AMED serves to recommend policies on political, social, and economic matters and to develop mutually beneficial initiatives to enhance relations between Asia and the Middle East. In light of the rise of radical religion and the violence, AMED serves as a platform to encourage tolerance, dialogue and coexistence among people. Finally, the platform seeks to become a voice of tolerance that accommodates and supports moderation in the face of troubling events transpiring across the world. 


\section{Core Principles}

As an entity that is regionally and globally acclaimed, AMED operates under a set of three basic principles, which apply to all participating members.

First, AMED is an inclusive body that is focused on nurturing, enhancing, and sustaining positive outcomes with the intention of promoting a broader cooperation among the Asian and Middle East Nations. Exemplifying this principle, the body offers voluntary, flexible and informal values as its basic working norms, with the intention of promoting tolerance and acceptance of different governing frameworks.

Secondly, AMED as a cross-country forum is based on the basic tenets of international law. The imperative need of basing their operations on international law is to ensure that each of the forum's members is held accountable for their actions by the rest of the sovereign states. In addition to this, by grounding its operations on international law, AMED as a cross-country platform ensures that relations and activities between the states are regulated with respect to the sovereignty of each state. As such, the forum ensures that each state secures the privilege of

enjoying its sovereignty, as none of the members present are allowed to intervene in the domestic affairs of their partners.

Thirdly, the forum seeks to respect the uniqueness and differences that define each of the diverse nations' values. By combining these principles, AMED aims to craft a forward-looking vision for Asia and the Middle East, which is based on support, collaboration, and respect for each other's contributions, capacity, and voice.

Singapore's Rationale for AMED

Singapore's role in AMED goes beyond just being the founding state and the venue of the first AMED meeting. Following the first meeting, human resource development was detected as one of the common issues faced by the participant countries. Consequently, AMED has 
provided a platform for Singapore to make solid progress in the level of cooperation between itself and its Middle East counterparts, particularly in the field of human resource development. Singapore's key contribution in this regard is through the establishment of regional centers for training in both Qatar and Jordan. The AMED Regional Vocational Training Centre (RVTC) in Jordan in a similar fashion is a collaborative effort between Singapore and Jordan, but differs from its Qatari equivalent in that it focuses on training in air conditioning and heating system maintenance and diagnostics with a focus on the construction industry.

\section{Qatar-Singapore Regional Training Centre for Public Administration (RTCPA) ${ }^{6}$}

RTCPA was founded in November 2006 under the auspice of AMED to focus on human resource development in the areas of governance, commerce, urban development and public service with a focus on civil servants. Since its establishment, over 485 officials from 39 AMED member states have benefitted from training at RTCPA under the diverse courses it offers.

RTCPA is currently located at the Institute of Public Administration of Qatar (IPA) in Doha. The IPA, established by the Amiri Decree in 1997, is RTCPA's sole affiliate institution in the region and is under the purview of Ministry of Administrative Development, Labour and Social Affairs. IPA is in charge of applied research, training and consulting with regards to administrative processes and practices. The official communications state that in the field of administration, finance and information technology, between 1997 and 2017, IPA has trained more than 11.000 participants and delivered 44 consulting studies for 18 governmental and private organisations.

\footnotetext{
${ }^{6}$ Unless otherwise stated, all technical information and data used in this section is a collection from the official documents of the involved governments. These documents include official information brochures for each course under Singapore Cooperation Programme and Singapore- Qatar Third Party Training Programme taking place in RTCPA, and official letters from the Singapore authorities to the governments in AMED for call for applications to the trainings. The details about the documents are offered in the references.
} 
IPA's partner from Singapore for coordinating RTCPA Trainings is Singapore Cooperation Programme (SCP) managed by the Technical Cooperation Directorate of the Singapore Ministry of Foreign Affairs. Targeting to contribute to the development of other developing countries, SCP was established in 1992 to offer technical assistance and training in line with the needs of those countries. In the context of SCP, until 2017, over 115.000 officials from 170 countries participated in the training courses and study visits sponsored by Singapore.

Strong governing policies, motivated civil service as well as strong deterrence mechanisms against corruption have been major pillars in Singapore's successful public administration model. Accordingly, overall, these training mechanisms target to foster a process of policy learning which is expected to result in the transfer of these best practices and values. To this end, in the context of RTCPA, key principles in Singapore's public administration system and Singapore's experience regarding the successes and failures in the path towards good governance are at the heart of the trainings.

In terms of content, the trainings cover a wide range of courses and content such as "Public Administration and Governance" or " E- Government- Towards Public Sector Excellence". The courses touch upon topics which lie in the core of good governance and efficient performance, including the adaptation of the Balanced Scorecard (BSC) performance system in the Singapore public service, organizational excellence frameworks, performance and outcome based budgeting, whole-of-government and ministry report cards, introduction to the Singapore Public Service, performance management and its implementation in the Singapore public service, human resource management and development framework. Table 1 offers a summary of the courses offered by RTCPA. 
Table 1: Courses offered by RTCPA

\begin{tabular}{|c|c|c|}
\hline $\begin{array}{l}\text { Negotiating Capacity } \\
\text { Building for the Free } \\
\text { Trade Agreement }\end{array}$ & Strategic Management & $\begin{array}{l}\text { Sustainable Cities } \\
\text { Planning and } \\
\text { Environmental } \\
\text { Management }\end{array}$ \\
\hline Planning of Land Use & $\begin{array}{l}\text { Excellence in Quality of } \\
\text { Service }\end{array}$ & $\begin{array}{l}\text { Economic Development - } \\
\text { The Experience of } \\
\text { Singapore }\end{array}$ \\
\hline $\begin{array}{l}\text { Production and Quality of } \\
\text { Management }\end{array}$ & Management of Change & $\begin{array}{l}\text { The e-government } \\
\text { towards discrimination in } \\
\text { the public sector }\end{array}$ \\
\hline $\begin{array}{l}\text { Project Management in } \\
\text { the Public Sector }\end{array}$ & $\begin{array}{l}\text { Management of work } \\
\text { pressures }\end{array}$ & $\begin{array}{l}\text { Partnership between the } \\
\text { Public and Private Sector }\end{array}$ \\
\hline $\begin{array}{l}\text { Human Resources } \\
\text { Management in the Civil } \\
\text { Service }\end{array}$ & Events Management & $\begin{array}{l}\text { Analysis of the General } \\
\text { Policy }\end{array}$ \\
\hline Education Organizations & $\begin{array}{l}\text { The Institutional } \\
\text { Performance Assessment }\end{array}$ & $\begin{array}{l}\text { The Role of the Public } \\
\text { Sector in Promoting } \\
\text { International Trade and } \\
\text { the Impact of the Recent } \\
\text { Financial Crisis on the } \\
\text { World Economy - The } \\
\text { Experience of the State of } \\
\text { Qatar }\end{array}$ \\
\hline
\end{tabular}

As a whole, each course offered in RTCPA creates a venue to examine Singapore's approach towards governance and policymaking, management tools, and information and communication technologies (ICT), their effective usage with the partnership of different ministries and how the principles in Singapore's experience have been translated into public policies, in the relevant fields. 


\section{RTCPA Trainings in Practice:}

\section{Enrolment and Selection of Trainees}

RTCPA has been striving to achieve its primary objective of fostering cooperation by holding about five training programs each year, in which approximately 60 employees on average participate. The application procedure to RTCPA's programs involve both the governments of AMED and the potential participants. The call for applications are communicated to all the AMED countries, such as Sri Lanka or India, and African countries, by official letters from Singapore Ministry of Foreign Affairs on behalf of the governments of Singapore and Qatar. With these "calls" Singapore and Qatar invite these countries to nominate up to two or three suitable applicants for consideration.

Initially, individuals working in the public administration institutions apply personally to their departments. Their consideration and selection is based on the approval of their department. After collecting the applications within their ministries, all nominations are managed by the respective government institutions. The final candidates' application files are submitted to the Ministry of Foreign Affairs, Singapore through the National Focal Point and the Singapore Embassy in the nominating country. The final list of participants are selected through the consultation of Singapore and Qatar.

The participant profile is officially identified as mid- to senior-level officials from Asian and Middle Eastern government agencies, below the age of 50, with fluent English and good health. However, in the selection process, former participants have noted that individuals with a Master's degree in the fields of economics, international affairs, political science, or 
management have a significantly higher chance of being enrolled. Nonetheless, the selected trainees are roughly evenly divided by gender, and between Qatari and non-Qatari nationals.

\section{Teaching and Course Delivery}

The courses take place in Doha at the Asia- Middle East Dialogue (AMED) Regional Training Centre for Public Administration (RTCPA). In terms of policy learning for the case of RTCPA, we can state that Singapore operates as a benchmark for best-practices and Qatar operates as the necessary environment for the learning to actually take place. The courses are offered by experts and trainers from Singapore. The trainings take place in an interactive and experimental setting allowing the participants to exchange their experiences, learning and challenges.

Under the Singapore-Qatar Third Country Training Programme Singapore-Qatar TCTP, the courses are jointly sponsored by Singapore and Qatar. Singapore undertakes the cost of training fees, airfares, insurance and accommodation for the instructor, while Qatar sponsors the cost of training facilities in Doha including classrooms, training aids, translation and utilities. Only the travel costs and accommodation of the participants are paid by the nominating authority.

\section{Evaluating RTCPA in Qatar}

Based on our detailed examination of official documents, we have found that RTCPA trainings clearly reflect high motivation of both Singapore and Qatar to initiate an inclusive, allencompassing platform with a broad scope of content so as to cover almost every necessary item in the recipe for successful development. Nevertheless, its implementation and fulfillment of its duty as a policy learning tool for an eventual policy transfer is not without shortcomings and challenges. 
In terms of applicants to the RTCPA, Ministry of Administrative Development, Labor \& Social Affairs, Ministry of Development Planning and Statistics, Ministry of Economy and Commerce, Ministry of Interior and Ministry of Public Health have been dominant. As mentioned above, to enroll for a training, the individuals have to apply first to their relevant government authorities to be included in the selection process. This is an advantage given that the process starts with the willingness of the actual participant, rather than a compulsory appointment by their managers. This can ensure to a certain extent that the participant it "open" for learning major messages of the courses and to socialize with a higher interest. Another strength is that the target groups are mid-level public officials, below the age of 50, as opposed to managerial level. Assuming that the participant continues his/her career in the public sector, this ensures that the principles and lessons of Singapore's experience covered in the courses can transfer to the relevant institutions for longer terms with higher inter-personal interaction. It is also possible to expect that former participants as mid-level officials can apply major take-aways of the courses once and when they become managers themselves so that we can talk about a spill-over effect within the public administration.

On the other hand, the diversity of participants which is a positive aspect of RTCPA inherits some shortcomings. The duration of the trainings are very short and include participants from more than 30 countries, with different national contexts, priorities and needs. To what extent the trainings can meet the expectations of the participant countries remain as a question mark. Although detailed data on the demographics of the participants is not publicly available, our informal discussions with the participants revealed that there is pessimism towards the intended impact of the RTCPA program. It was noted: despite the fact that Qatari representation has been higher than what has been stated on the agreement upon the Memorandum of Understanding (which designed the training programs to host an average of two Qatari nationals 
per program), still, the size of the Qatari employee based in public sector was not considered as enough to benefit from RTCPA. According to past beneficiaries of the program, the impact of the forum is low as trainings do not really equip participants with potential ideas and solutions to apply course material into their professional occupations.

Therefore, in designing the courses, it is a big challenge to pay attention to contextual factors and to avoid staying at a macro level. As the trainers are predominantly Singaporean public sector and policy representatives, along with academics and sector specific experts, naturally the delivery of the program is more Singapore centric. While presenting the bestpractices of Singapore is the main purpose of the trainings, it is of equal importance to offer possible ways of emulating from its experience through materials used and applications.

Policy-wise, Qatar already has a national development strategy and a framework for its projects and targets. Indeed, the RTCPA trainings does not stress policy formulation and development anyway. Consequently, regarding policy practices, we expect the transfer to be on the implementation side, on project management skills, on applications of technology and management skills. For a successful transfer process, it is of crucial importance to adjust unique Singapore experiences and practices reflected in the courses for the Qatari context, or for an Islamic society.

Application-wise, classroom training is a conceptual pillar and application is pedagogically different. What has been the impact of RTCPA training on actual practice remains another question mark. Apart from the benchmarking studies which are already done in preparation of QNV 2030 and NDS, what is the current Singaporean footprint in Qatar's progress in public sector excellence is interesting, yet very difficult to discover. "Is it possible to trace an effect from the classroom to the front-lines of administration?" is an instrumental question to assess the real success of RTCPA, which begs further research. 
The logic of policy transfer implies a socialization process, where the transfer is deeper and long-lasting if it creates a shared policy language, and shared communities of practice. It is a fact that RTCPA offers the appropriate venue for this purpose by bringing civil servants from across AMED. Nevertheless, we do not know whether RTCPA training build and socialize communities within Qatari ministries (or across government, given the small size of the Qatari state administration) and across Qatari ministries and counterparts in Singapore in addition to bilateral agreements. We suggest that following RTCPA training, follow-up events, presentations or workshops organised by the participant him/herself are necessary to deliver major take-aways inside and across Qatari ministries to increase the multiplied effect of the RTCPA training and to interactively discover ways to adopt them into their own context.

\section{Conclusion:}

The AMED forum is a unique platform that was conceived with the intention of developing and enhancing mutual understanding among the members of Asia and Middle East Asia. Most of the discussions within the platform revolved around security issues, cultural transformations, scientific growth, political concerns, educational reformations, and economic vulnerabilities. As examined in detail the platform also included RTCPA as a concrete tool for policy learning and transfer.

It is a fact that Qatar, compared to other Middle East countries, is highly abundant in resources and wealth despite it being small in physical size. Nevertheless it acknowledges the importance of economic diversification and it is strategically diversifying to shift away from hydrocarbon-based economy towards knowledge-based economy (Sever, Tok, D'Allessandro, 2019). To this end, this article examined the interaction between Singapore and Qatar as an instance of policy transfer between a successful case of development and an ambitious case in 
transition through exclusive focus on human capital development in public policy making and public administration.

Building on the distinction between strategic learning and social learning, we suggested that the cooperation between Qatar and Singapore and broader platform of AMED is clearly designed as a venue where social learning can take place, since neither conditionality nor strategies for acceptance to a certain "club" are valid for these cases. It is, however, true that it is in the strategic interest of Qatar to learn from the case of Singapore and to transfer its best practices but this is not with the expectation to fulfill a conditionality or to be granted a membership. As mentioned earlier this is a totally voluntary agreement. Nevertheless, social learning is strategically crucial for Qatar as only internalizing major principles of good public administration can result in actual national development. The values identified in the targets of NDS cannot be achieved without sincere adaptation of the actions and minds to the 21th century.

In this context, we further evaluated the case of RTCPA Trainings as a mechanism to foster this policy transfer. We took the RTCPA case, as an actual effort for policy transfer through social learning as it included an interactive socialization platform based on voluntary application of the participants and it intended a change in the ideas and values of the participants, and even a change in the identity of public administration in their home countries. Nevertheless, the impact achieved by RTCPA so far has not been in its full potential. There is a need to energize and transform AMED, and its RTCPA extension as a move to ensure the relevancy of the platform in fostering cooperation, growth and human capital development.

We have found that along with the lack of data availability about RTCPA, there is also a failure to measure the results and effects of the trainings. Tracing the success of the trainings, their return to the home institutions and their effectiveness should be monitored. In this regard, 
transparent statistics by years, by countries and by trainings as well as participant demographics would also activate an innovative environment for research and policy making.

Among its advantages and shortcomings, we also noticed that one of the major challenges for this case is the fact that there is no single recipe for all the developing countries. It is not clear that the "best practices" will equally work for every country. Moreover, it is also critical how the trainees perceive the lessons from the best practices in the light of their own national settings, culture and needs. Although RTCPA is open for progress as a tool of policy transfer, unless the trainings are adapted to the national settings and national strategies we cannot talk about a successful policy transfer.

Still, building on their history of bilateral relations, the cooperation between Qatar and Singapore inherits huge potential, given that both parties aspire for efficient governance, innovative smart societies and sustainable development.

\section{Declaration of conflicting interests}

The Authors declare that there is no conflict of interest.

\section{References}

Agonia, A. (2018). Qatar-Singapore trade relations excellent and continue to grow. Qatar Tribune, July 1.

Broome, A., \& Seabrooke, L. (2012). Seeing like an international organization. New Political Economy, 17 (1), 1-16.

Broome, A., \& Seabrooke, L. (2015). Shaping policy curves: Cognitive authority in transnational capacity-building. Public Administration, 93(4), 956-972. doi:10.1111/padm.12179

Börzel, T. \& Risse, T. (2003). Conceptualizing the Domestic Impact of Europe. In K. Featherstone \& C. Radaelli (Eds.) The Politics of Europeanization (pp. 57-83). New York: Oxford University Press.

Bürgin, A. (2014). Strategic Learning, Limited Europeanization: How the Turkish National Police Used Twinning to Prepare Itself for the Planned New Border Agency. Turkish Studies, 15 (3), 458-75.

Cafiero, G. (2017). ASEAN and the Qatar Crisis. The New Atlanticist, November 3.

Checkel, J. T. (1998). The Constructivist Turn in International Relations Theory. World Politics, $50(2), 324-348$.

Checkel, J. T. (1999). Social Construction and Integration. Journal of European Public Policy, 6 (4), $545-560$. 
Checkel, J. T. (2005). International Institutions and Socialization in Europe: Introduction and Framework. International Organization, 59 (4), 801-826.

Dolowitz, D., \& Marsh, D. (1996). Who learns what from whom: A review of the policy transfer literature. Political studies, 44 (2), 343-357.

Dolowitz, D. P. \& March, D. (2000). Learning from Abroad: The Role of Policy Transfer in Contemporary Policy-Making. Governance 13 (1), 5-24.

Grabbe, H. (2002). Europeanization Goes East: Power and Uncertainty in the EU Accession Process, Paper for the ECPR Joint Sessions of Workshops Turin, March 22-27.

Hadjiisky, M., Pal, L. A., \& Walker, C. (Eds.). (2017). Public Policy Transfer: Micro-Dynamics and Macro-Effects. Cheltenham, UK: Edward Elgar.

Luo, S. (2017). Qatar and Singapore reaffirm ties; boost industry, business cooperation. The Business Times, October 17.

Ministry of Development Planning and Statistics. (2012). Results of Research and Development Survey In The State of Qatar.

Pal, L. A., \& Clark, I. D. (2016a). The MPA/MPP in the Anglo-democracies: Australia, Canada, New Zealand, the United Kingdom, and the United States,. Policy and Society, 35(4), 299313. doi:http://dx.doi.org/10.1016/j.polsoc.2016.11.001

Pal, L. A., \& Clark, I. D. (2016b). Teaching public policy: Global convergence of difference? Policy and Society, 35(4), 283-297.

Peninsula. (2017). Qatar-Emir's visit cements ties with Singapore. October 17. Retrieved from http://thepeninsulaqatar.com/article/18/10/2017/Emir\%E2\%80\%99s-visit-cements-tieswith-Singapore

Peninsula. (2018). Singapore Business Council in Qatar to foster closer ties. May 6. Retrieved from https:/www.thepeninsulaqatar.com/article/06/05/2018/Singapore-BusinessCouncil-in-Qatar-to-foster-closer-ties.

Qatar Chamber. (2018). Qatar, Singapore Trade Volume Reaches \$6.4 Billion. April 16. Retrieved from https://qatarchamber.com/qatar-singapore-trade-volume/.

Qatar Foundation. (2016). Investing in research and Innovating for Society. Qatar Foundation Annual Research Conference, 22-23 March.

Qatar National Development Strategy 2011-2016. Qatar General Secretariat for Development Planning. First published March 2011.

Risse, T., Cowles, M.G. \& Caporaso, J. (2001). Europeanization and Domestic Change: Introduction. In M.G. Cowles; J. Caporaso \& T. Risse (Eds.), Transforming Europe. (pp. 1-21). New York: Cornell University Press.

Schimmelfennig and Sedelmeier. (2005).The Europeanization of Central and Eastern Europe, Cornell University Press.

Schneider, Volker and Hage, Frank. (2008). Europeanization and the retreat of the state. Journal of European Public Policy, 15 (1), 1-19.

Sever S.D., Tok, M. E. \& D'Alessandro, C. (2019). Global Environmental Governance and the GCC: Setting the Agenda for Climate Change and Energy Security. In L. Pal \& M.E. Tok (Eds.) Global Governance and Muslim Organizations. International Political Economy Series. Palgrave Macmillan.

Sever, S.D. (2018). Turkey's nuclear energy policy in the context of environment: a case of Europeanization?, Turkish Studies,. DOI: 10.1080/14683849.2018.1500138

Singapore Cooperation Programme. (2010). Singapore- Qatar Third Country Training Programme General Information Brochure 8 March to 11 March 2010.

Singapore Cooperation Programme. (2018). Singapore- Qatar Third Country Training Programme General Information Brochure, January. 
Singapore High Commission New Delhi. (2009). Communication from Tan Ding Yong to Kumar Sanjay Krishna, 8 October.

The Straits Times. (2017). Singapore, Qatar strengthen bilateral ties, October 18. Retrieved from https://www.straitstimes.com/singapore/singapore-qatar-strengthen-bilateral-ties

Tok, M. E., Alkhater, L., \& Pal, L. A. (Eds.). (2016). Policy-Making in a Transformative State: The Case of Qatar. London: Palgrave Macmillan.

Yew, L. K. (2000). From Third World to First: The SIngapore Story: 1965-2000. Singapore: Marshall Cavendish Editions.

Why Smart Nation. (2018). Smart Nation and Digital Government Office Singapore. Retrieved from https://www.smartnation.sg. 